\title{
Análisis básico de parámetros físico-químicos y bacteriológicos del agua potable de Telpaneca, Madriz, Nicaragua
}

Cipriano López ${ }^{1}$ y David Martínez ${ }^{2}$

1. Docente e investigador de la Facultad de Ciencia, Tecnología y Ambiente de la Universidad Centroamericana (UCA). Apdo. 69, Managua, Nicaragua. E-mail: ciprianoall@yahoo.com

2. Estudiante de la Facultad de Ciencia, Tecnología y Ambiente de la Universidad Centroamericana (UCA). Apdo. 69, Managua, Nicaragua. E-mail: mareveno@yahoo.com

Recibido: septiembre de 2006 / Aceptado: octubre de 2006

ESTE ARTÍCULO PRESENTA EL ESTUDIO FÍSICO-QUÍMICO Y BACTERIOLÓGICO del agua potable de la ciudad de Telpaneca como una iniciativa para comprobar afirmaciones contradictorias entre el MINSA y ENACAL. El primero mantiene que esta agua está contaminada principalmente con Coliformes Fecales; mientras que el segundo por su parte sostiene que brinda un servicio seguro. Con este estudio se afirma que esta agua está contaminada con Magnesio y Coliformes Fecales sobre las NORMAS CAPRE. Por tanto se recomienda completar el análisis del agua para su potabilización.

Palabras clave: Agua potable-investigaciones / análisis del agua-Telpaneca, Madriz (Nicaragua) / calidad del agua / contaminación del agua

\section{Introducción}

La calidad del agua potable es un requerimiento a cumplir para brindar a la población mejor seguridad sanitaria al consumir el vital líquido. El agua de beber requiere ser adecuada para el consumo humano y para todos los usos domésticos corrientes. Por eso es necesario realizar estudios de la calidad de ésta.

Esta calidad se clasifica de acuerdo a la concentración de los constituyentes presentes y éstos no deben indicar ningún riesgo significativo para la salud del consumidor a lo largo de toda una vida (OMS, 1998).

Para determinar la calidad del agua se tienen ciertos parámetros; cuando éstos se rebasan 
hay que averiguar la causa y adoptar una medida correctiva. Estos parámetros son: fisicoquímicos y microbiológicos.

En un plano ideal, el agua de beber no debe contener ningún microorganismo del que se sepa que es patógeno, ni ninguna bacteria indicativa de contaminación fecal. Para asegurarse que un abastecimiento de agua está libre de patógenos es necesario examinar periódicamente muestras de agua. La detección de escherichia coli constituye una prueba decisiva de contaminación fecal. En la práctica, la detección de coliformes fecales constituye una alternativa aceptable.

Los parámetros físicos a considerar para la calidad del agua son: la turbidez, el color, el sabor y el olor.

Los parámetros críticos de la calidad del agua son los siguientes:

- $\quad$ E. coli; los coliformes fecales son aceptados como sustitutos adecuados.

- $\quad$ cloro residual (si se practica la cloración)

Estos parámetros deben complementarse, cuando sea apropiado, con los siguientes:

- $\quad$ pH(si se practica la cloración);

- $\quad$ turbidez(si se efectúa algún tratamiento)

Estos parámetros críticos se pueden medir in situ con un equipo de ensayo sencillo. El ensayo in situ es indispensable para determinar la turbidez y el cloro residual, ya que estos cambian rápidamente durante el transporte y el almacenamiento.

Es importante determinar los parámetros químicos, pues un número considerable de problemas muy graves pueden ser resultado de la contaminación química de los hídridos. La presencia de nitrato y nitrito en el agua puede ser el resultado de una aplicación excesiva de fertilizantes, o de la lixiviación de aguas servidas, o de otros desechos orgánicos en las aguas subterráneas o superficiales. La presencia de altas concentraciones de plomo puede afectar el desarrollo mental de los niños. La exposición a concentraciones altas de fluoruros naturalmente presentes en el agua puede causar la aparición de manchas en los dientes y, en los casos graves, fluorosis del esqueleto e invalidez. La presencia de arsénico naturalmente puede representar un riesgo para la salud.

Según lo indica el capítulo 18 del Orden del día 21 de la CNUMAD, en la mayoría de los países los principales riesgos para la salud humana asociados al consumo de agua contaminada son de tipo microbiológico. Aproximadamente el 80\% de todas las enfermedades y más de una tercera parte de las defunciones en los países en desarrollo son causadas por el consumo de agua contaminada.

En nuestro país el acceso de la población al sistema de agua potable, es un problema nacional. Lo cierto es que 120 (80\%) de los 151 municipios del país que elaboraron un Plan Ambiental Municipal en el marco del Plan Nacional Ambiental en el año 2000-2001, identifican el abastecimiento de agua potable como su principal problema ambiental. De acuerdo al PNUD, el 70.5\% de la población tenía acceso a agua potable en el año 2001. En el área rural este porcentaje es mucho menor: sólo el 46\% tiene acceso a una fuente de agua segura. En el área urbana, uno de cada diez nicaragüenses no cuenta con el vital líquido. 
El Plan Nacional de Salud -presentado en agosto del 2004- asevera que sólo un tercio de la población del país tiene agua para beber dentro de la vivienda y otra tercera parte lo tiene fuera. Como es de esperarse en un país con significativos niveles de inequidad, este porcentaje se distribuye desigualmente entre los departamentos del país y según la condición socio-económica de la población. En el área rural, sólo 26\% recibe agua de cañería, el 36\% usa pozos privados o públicos y el $24 \%$ toma agua de ríos, manantiales o quebradas.

Telpaneca es un municipio en el Departamento de Madriz al Norte de Nicaragua. Cuenta con una población en el casco urbano de 3,981 personas, que pertenecen a 685 familias y habitan 670 viviendas. Al igual que otros municipios, el acceso y la calidad del agua potable es un problema, ya que sólo el $52 \%$ del total de viviendas cuentan con este servicio domiciliar y el 48\% la adquiere directamente del Río Coco, siendo éste la principal fuente de agua que atraviesa la zona. Además con el servicio existente, surge la sospecha de que el agua está contaminada y, según el MINSA, es la causa principal de los problemas de salud en la población (CENAGRO, 1998.)

Para conocer la calidad real del agua potable de este municipio, se llevó a cabo esta investigación, que consistió en tomas de muestras de cinco sitios representativos de la ciudad y se les realizó ensayos físico-químicos y bacteriológicos, definiendo los siguientes parámetros: Color, olor, sabor, turbiedad, conductividad, pH, temperatura, Calcio, Magnesio, Dureza, Alcalinidad, Nitratos, Nitritos, Cloruros, Cloro residual y Coliformes Fecales. (NORMAS CAPRE1)

Dichos parámetros se seleccionaron como básicos para obtener un indicador acerca de la calidad del agua potable en la zona seleccionada. Aunque existen otros parámetros importantes, en este estudio no se tomaron en cuenta.

\section{Metodología}

\section{1 Área de estudio}

El área de estudio corresponde a cuatro barrios representativos de la ciudad de Telpaneca, Municipio del Departamento de Madriz, ubicado a $218 \mathrm{Km}$ al Norte de la Capital Managua en la República de Nicaragua. La ciudad está asentada dentro de un relieve accidentado que va desde los $496 \mathrm{msnm}$ en la rivera del Río, hasta los $535 \mathrm{msnm}$ en la parte más alta de los Barrios.

La metodología del estudio consistió en el análisis in situ, para lo que se requirió transportar equipo de campo con la cristalería previamente esterilizada. Otros parámetros se midieron en el laboratorio, para lo que se utilizaron botellas winklers esterilizadas y bolsas especiales para muestreo microbiológico. Éstas sirvieron para transportar las muestras y analizarlas en un período comprendido dentro de las veinte y veinticinco horas después de haber tomado la muestra, esto según el parámetro a medir.

Para obtener mejor precisión y confianza en los resultados, los ensayos se realizaron tanto en el Laboratorio de Química de la Universidad Centroamericana, como en el Laboratorio 
del CIDEA que está dentro de la misma Universidad, y en los Laboratorios de química y de microbiología de la Universidad Nacional de Ingeniería.

Se efectuaron siete muestreos y ensayos en un período de cinco meses con el objetivo de monitorear la presencia de ciertos parámetros sospechosos en dicha agua.

\section{Materiales y métodos}

Cuadro 1. Parámetros y métodos de análisis.

\begin{tabular}{|l|l|}
\hline Parámetros & \multicolumn{1}{|c|}{ Método de análisis } \\
\hline Alcalinidad total & Volumétrico con indicador o titulación \\
\hline Dureza total & Volumétrico con EDTA \\
\hline Dureza de calcio & Titulométrico - Volumétrico con EDTA \\
\hline Magnesio & Volumétrico \\
\hline Nitritos & $\begin{array}{l}\text { Fotométrico con ac. Sulfanílico y } \\
\text { 1- naftilamina en medio ácido }\end{array}$ \\
\hline Nitratos & $\begin{array}{l}\text { Fotométrico mediante la reducción de } \\
\text { iones nitratos a nitritos }\end{array}$ \\
\hline Turbiedad & Turbidimétrico \\
\hline Cloruros & Fotométrico \\
\hline Cloro residual & $\begin{array}{l}\text { Fotométrico N,N - dietil } \\
\text { Fenilendiamina (DPD) }\end{array}$ \\
\hline Cloro total & $\begin{array}{l}\text { Fotométrico } \text { N,N - dietil } \\
\text { Fenilendiamina (DPD) }\end{array}$ \\
\hline pH & Electrométrico \\
\hline Coliformes fecales & Filtro de membrana \\
\hline Temperatura & De campo \\
\hline Color de agua & Observación (cualitativo) \\
\hline Sabor de agua & Gusto (cualitativo) \\
\hline Conductividad & De laboratorio \\
\hline & \\
\hline
\end{tabular}

Fuente: Métodos Normalizados para el análisis de aguas residuales y potables (1992); Normas técnicas de aguas potables y Residuales del Ministerio de Salud de Nicaragua (1998).

La parte experimental de esta investigación se llevó a cabo en dos momentos: un momento de campo y otro en laboratorio; esto debido a que el ensayo de varios parámetros se debe realizar in situ.

\section{Resultados}

Las medidas de los diferentes parámetros tomadas durante los cinco meses del estudio, se resumen en el cuadro 2. 


\section{Resultados}

Cuadro 2. Resultados cuantitativos de ensayos de parámetros físico-químicos y bacteriológicos del agua potable de Telpaneca, Madriz.

\begin{tabular}{|c|c|c|c|c|c|c|c|c|}
\hline \multirow[b]{2}{*}{ Parámetro } & \multicolumn{6}{|c|}{ Valores obtenidos } & \multicolumn{2}{|c|}{$\begin{array}{l}\text { Valor permitido } \\
\text { (NORMAS CAPRE) }\end{array}$} \\
\hline & Pila 1 & $\begin{array}{l}\text { Pila2 } \\
\end{array}$ & Zona1 & Zona2 & Zona3 & Zona4 & Valor quía & Máximos permisible \\
\hline $\begin{array}{l}\text { Alcalinidad total } \\
(\mathrm{mg} / \mathrm{L})\end{array}$ & 262 & 238 & 228 & 236 & 256 & 236 & nvg & nvm \\
\hline $\begin{array}{l}\text { Dureza total }(\mathrm{mg} / \mathrm{L} \\
\left.\mathrm{CaCO}_{3}\right)\end{array}$ & 242 & 192 & 224 & 196 & 208 & 198 & 400 & $\mathrm{nvm}$ \\
\hline Calcio $\left(\mathrm{mg} / \mathrm{L} \mathrm{CaCO}_{3}\right)$ & 70,14 & 64,93 & 66,13 & 66,53 & 66,5 & 70,14 & 100 & nvm \\
\hline $\begin{array}{ll}\text { Magnesio } \\
\left.\mathrm{CaCO}_{3}\right)\end{array} \quad(\mathrm{mg} / \mathrm{L}$ & 171,86 & 127,07 & 157,87 & 129,47 & 141,47 & 127,86 & 30 & 50 \\
\hline Nitratos $\mathrm{NO}_{3}(\mathrm{mg} / \mathrm{L})$ & 5,6 & 5,4 & 4,9 & 5,4 & 4,7 & 0,5 & 25 & 50 \\
\hline Nitritos $\mathrm{NO}_{2}(\mathrm{mg} / \mathrm{L})$ & 0,01 & 0,01 & 0,01 & 0,01 & 0,02 & 0,01 & nvg & (1) \\
\hline $\begin{array}{l}\text { Conductividad } \\
(\mu \mathrm{s} / \mathrm{c} \mathrm{m})\end{array}$ & 567,7 & 564 & 557,3 & 563,7 & 514,3 & 567 & 400 & nvm \\
\hline Turbiedad (UNT) & 0,55 & 5,2 & 6,23 & 0,63 & 0,69 & 0,56 & 1 & 5 \\
\hline Cloruros (mg/L) & 0,5 & 0,1 & 0,35 & 0,55 & 0,36 & 0,22 & 25 & 250 \\
\hline Cloro residual $(\mathrm{mg} / \mathrm{L})$ & 0,92 & 0,6 & 0,1 & 0,47 & 0,21 & 0,7 & $0,5-1,0$ & nvm \\
\hline $\mathrm{pH}$ & 6,6 & 6,6 & 6,9 & 6,7 & 6,7 & 6,8 & $6,5-8,5$ & nvm \\
\hline $\begin{array}{l}\text { Coliformes fecales } \\
\text { (cualitativo) }\end{array}$ & 0 & positivo & positivo & negativo & positivo & negativo & 0 & 0 \\
\hline Temperatura $\mathrm{T}^{\circ}$ & 28,8 & 29 & 27,8 & 27 & 26,8 & 26,6 & $18-30$ & nvm \\
\hline Color de agua & Incolora & Incolora & Incolora & \begin{tabular}{|l|} 
Incolora \\
\end{tabular} & Incolora & Incolora & - & - \\
\hline Sabor de agua & Insípida & Insípida & Insípida & Insípida & Insípida & Insípida & - & - \\
\hline Olor de agua & Inodora & Inodora & Inodora & Inodora & Inodora & Inodora & 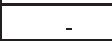 & - \\
\hline
\end{tabular}

nvg: no hay valor guía; nvm: no hay valor máximo; $\mu \mathrm{S} / \mathrm{cm}$ : micro por centímetro; mg/L: miligramos por litros; UNT: unidades nefelométricas de turbidez

Fuente: NORMAS CAPRE, hispagua.cedex.es/siagua/datos/calidad_iberoamerica.

\subsection{Resultados cualitativos}

La administración del servicio de agua potable en Telpaneca está a cargo de la Empresa Nicaragüense de Acueductos y Alcantarillados (ENACAL), y fue instalado en el año de 1958 con una capacidad para abastecer a trescientos quince hogares, pero en la actualidad se abastecen trescientos cincuenta.
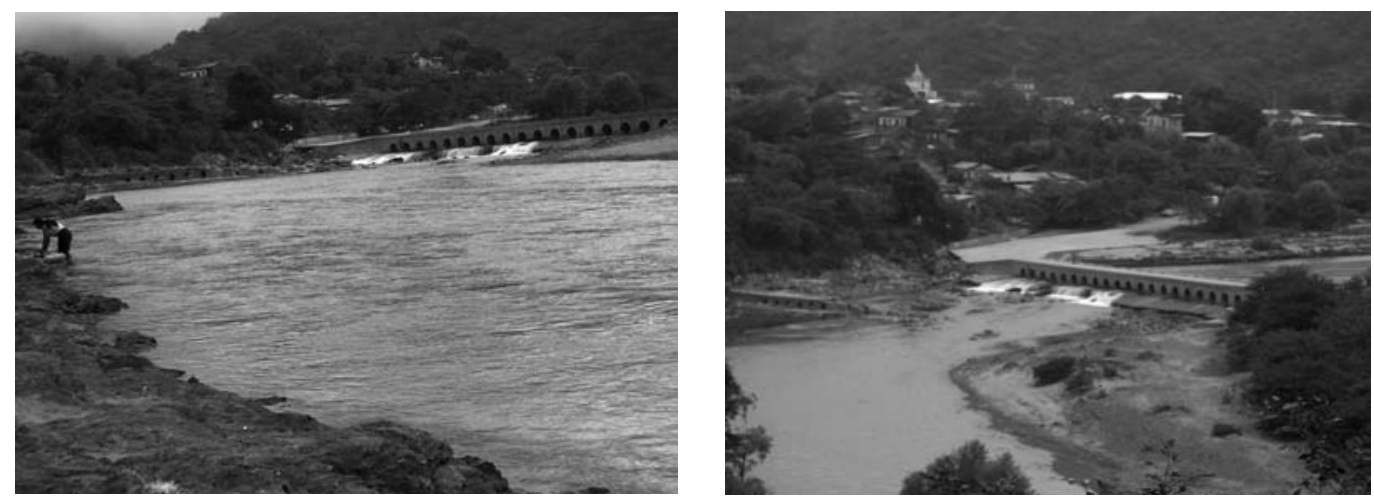

Ilustración 1. Río Coco, principal fuente de abastecimiento de agua en Telpaneca. 
El agua que usan los habitantes de Telpaneca para consumo humano es captada del manto freático del Río Coco a través de un tubo que posee un filtro para sedimentos (ambos tienen cincuenta años de funcionamiento aproximadamente), por medio del cual es transportada a una pila subterránea donde le agregan Hipoclorito de Calcio disuelto como desinfectante. Es diluido en agua y con dos sondas adiciona el compuesto a la pila que mide 40 pies de profundidad, después de diez minutos de bombeo de agua a una presión de 73 atm con ayuda de un Comparador 608-01 al cual deposita una tableta de 168 DPD-1 y luego agua; prueba cualitativamente si ésta está saliendo con $3.0 \mathrm{mg} / \mathrm{L}$ de cloro, si no, adiciona más compuesto diluido a la pila hasta obtener el valor necesario. Posteriormente el agua es bombeada, abasteciendo primero a cuatro barrios de la zona baja y luego llega a una primera pila de captación con capacidad de almacenamiento de 24,000 galones que abastece parte de un barrio, y se rebombea a una segunda pila capaz de almacenar 1,500 galones en la parte más alta, la cual abastece a dos barrios.

La tubería de distribución en su mayor parte es de asbesto cemento con un diámetro de tres pulgadas, y su tiempo de funcionamiento es igual al del filtro. La mínima parte es PVC, que se ha cambiado en las zonas donde ha habido mayores problemas de fuga de agua; el resto de tubería es de dos pulgadas.

Actualmente el suministro de agua es racionado por motivos de ahorro de energía y por la falta de capacidad del diseño para garantizar el suministro a la demanda actual existente. Por tal razón, en las noches la tubería queda vacía hasta la mañana siguiente que comienza el bombeo. En ese momento la población recibe por lo general un agua que lleva consigo una coloración café acompañada de material sólido en forma de un grano pequeño de arena negra que a mediados del día desaparece. Tal problema se da en toda la población. Además, un caso específico se presenta en la Zona No 1, donde la población ha recibido agua con olor pútrido.

Otro fenómeno que ocurre es, que si se comienza a almacenar agua en un recipiente blanco, con el tiempo (15 días) éste va tomando una coloración café negruzca, hasta que cambia totalmente de color, quedando café negra que sólo se desprende del recipiente si se lava con jugo de limón (ácido débil).

\section{Discusión}

Los resultados presentados en el cuadro 2 muestran que los parámetros de: Alcalinidad, Calcio, Nitritos, Nitratos, Turbiedad, Cloruros, pH, Temperatura, Color, Olor y Sabor se encuentran bajo norma.

Según los resultados del estudio, existen parámetros cuyas concentraciones están sobre la Norma CAPRE, y son: Magnesio, Coliformes Fecales y la Conductividad. A los dos primeros se les atribuye como causantes de enfermedades en la población.

Magnesio: Los resultados de Magnesio sobrepasan la Norma en los seis puntos de muestreo. Este parámetro está relacionado con la dureza del agua y, según los resultados, el agua de Telpaneca es dura ya que oscila entre 150 y $300 \mathrm{mg} / \mathrm{L}$ de $\mathrm{CaCO}_{3}$. $\mathrm{Al}$ encontrarse magnesio 
en aguas duras, en concentraciones mayores, y al estar disuelto en el agua, forma depósitos en la tubería.

El consumo controlado de Magnesio influye en la síntesis de proteínas, en la producción de energía, en el correcto funcionamiento del sistema nervioso y en el mecanismo de contracción muscular. Juega un papel vital en la transmisión de los impulsos nerviosos a través de los músculos y los nervios. Por otro lado, su exceso influye en el desarrollo de enfermedades cardiovasculares, inhibe la calcificación ósea y causa cálculos renales.

Coliformes Fecales: De los seis puntos de muestreo, tres de ellos (pila 2, zona No1 y zona No3), mostraron presencia de Coliformes fecales. Este problema microbiológico causa en la población, en la opinión de médicos del MINSA y de PROFAMILIA, enfermedades gastrointestinales originadas por la aparición de parásitos, los que -según el tiempo de vida en el sistema digestivo- se vuelven más difíciles de ser expulsados. De acuerdo a las estadísticas, este problema es el causante del 80\% de las enfermedades estomacales en la población.

La contaminación fecal del agua puede deberse a que la tubería de asbesto cemento está expuesta en zonas donde existen sumideros y letrinas. En este lugar el suelo es arenoso, lo que facilita el movimiento del agua contaminada, la que, al entrar en contacto con estos tubos dada la facilidad de filtración y su antigüedad (50 años de existencia), pasa a ser parte en el sistema de distribución, contaminando de esta manera el vital líquido.

Conductividad: El agua pura es un mal conductor de la electricidad. El agua potable es un buen conductor de electricidad debido a la presencia de sales minerales disueltas en ella, la que favorece la formación de iones en solución que aumenta la Conductividad.

Un valor alto de conductividad indica que en el agua existen ciertos parámetros (físicoquímicos) en concentraciones mayores o considerables.

\section{Conclusión y recomendaciones.}

De acuerdo al análisis de parámetros físico-químicos y bacteriológicos básicos, indicados por las NORMAS CAPRE, llevado a cabo en el agua potable de Telpaneca, se puede concluir y recomendar que:

El agua potable de Telpaneca es peligrosa para el consumo humano, ya que existe presencia de contaminación fecal y exceso de Magnesio.

El proceso de cloración que se le da al agua para desinfectarla no es eficiente para eliminar la contaminación fecal debido a factores como:

- La tubería del sistema de distribución no recibe por lo general mantenimiento de limpieza, lo que da lugar a la aparición de vida microbiana en sus paredes, afirmación que se soporta como resultado de la observación en microscopio de muestras de agua de diferentes puntos de Telpaneca en las cuales se observaron algas, protozoos y otros 
microorganismos no identificados en el momento; algunos de ellos pueden exigir cloro como alimento, bajando de esta manera la concentración de cloro residual que debe de poseer la tubería, para contra atacar la contaminación fecal específicamente.

- Se debe de mejorar el sistema de limpieza de la pila número uno o de captación, de manera que se pueda eliminar totalmente el agua de lavado.

- Al poseer la tubería este tipo de vida microbiana, no tener el suficiente cloro residual y permitir la incorporación de agua contaminada con Coliformes Fecales, no tiene entonces la capacidad de desinfección para eliminar microorganismos indicadores de contaminación fecal como es la Escherichia Coli.

- Como el proceso de cloración es manual, esto se vuelve cualitativo y menos preciso, por lo que se recomienda que los procesos del nuevo proyecto de potabilización deberán ser automáticos en su mayoría.

Es necesario desarrollar una investigación microbiológica completa del agua potable que contemple la parte virológica, para conocer en realidad su situación y correlacionarla con las diferentes enfermedades que el MINSA y médicos de PROFAMILIA atribuyen al consumo de esta agua. Por el momento, lo que se recomienda para desinfectar el agua que se va a ingerir, es exponer volúmenes de agua contenidos en recipientes blancos transparentes totalmente al sol, por un período aproximado de seis horas para que los rayos ultravioleta destruyan las bacterias contenidas en el vital líquido. Dicha recomendación se hace debido a que toda la población no tiene los ingresos necesarios para adquirir agua purificada.

La fuente de alimentación de agua (Río Coco), para tratarla y distribuirla a la población, es indicada; aunque sí se debe de realizar una caracterización completa de esta agua cruda ( que existe sospecha de la presencia de algún metal pesado, ya que estas aguas reciben cargas de aguas contaminadas con desechos de producción agrícola, aguas provenientes de diferentes actividades en la ciudad de Ocotal, Dipilto, etc. Así se le podrá dar un tratamiento de potabilización, que debe de consistir en la remoción de las concentraciones de parámetros que estén sobre la Norma -como es el caso del Magnesio- ajustándolos de esta manera a los requerimientos de la Norma para obtener y brindar un servicio de agua potable apto para el consumo humano.

Lo anterior se recomienda debido a que no se tiene acceso a otra fuente de abastecimiento de agua con esa capacidad. Pueden existir otras fuentes, pero el costo para hacer llegar el agua al sistema de tratamiento y a la población sería muy elevado.

En cuanto a la coloración café-negra observada en las paredes de los recipientes, en el desarrollo de este estudio no se comprobó a qué se debe, pero sí es importante mencionar que esta coloración es propia de elementos químicos como el Hierro y el Manganeso, para lo cual se necesita su incorporación en nuevos ensayos de Laboratorio, con el fin de medir y conocer sus concentraciones en el agua. 
Es importante que las autoridades pertinentes (Alcaldía y ENACAL) tomen en serio este asunto y realicen las gestiones necesarias para brindar a la población un servicio de agua potable seguro, tomando en cuenta el estudio previo del agua que se recomienda y la valoración sobre la fuente de alimentación de la misma. Dicho servicio debe ser diseñado para beneficiar a todos los hogares de Telpaneca, ya que existen seiscientos setenta y sólo trescientos cincuenta obtienen este beneficio; el resto consume agua directamente del río, lo que representa un riesgo extremo para la seguridad de la salud de esta población.

\section{Agradecimientos}

Agradecemos de manera categórica al Msc. Iván Marín, Director de Investigación y Proyección Social de la Universidad Centroamericana, a la Msc. Vera Amanda Solís, Decana de la Facultad de Ciencia, Tecnología y Ambiente de la Universidad Centroamericana, a la Msc. Indiana García, Docente de nuestra Alma Mater, al Msc. Rodolfo Espinoza, Docente de la UNI, al Lic. José Domingo Sandoval, Responsable administrativo de la Facultad de Ciencia, Tecnología y Ambiente, a la Alcaldía Municipal de Telpaneca y a ENACAL-Telpaneca y Estelí por su incondicional apoyo en el desarrollo de esta investigación.

\section{Notas}

1 La investigación se basó en las normas de calidad (CAPRE), que es un estándar definido para ser utilizado en Centroamérica, Panamá y República Dominicana, debido a que existen países del Istmo como Nicaragua que no cuentan con estándares de calidad de agua potable.

Para conocer las diferentes concentraciones de los parámetros químicos y bacteriológicos, se realizaron ensayos o marchas analíticas en laboratorio con cada una de las muestras.

Se le denomina parámetros de calidad a ciertas concentraciones o características físico-químicas y bacteriológicas que se deben de medir para que sean indicadores de la composición de cierta agua

\section{Referencias bibliográficas}

-Análisis de aguas potables y residuales [en línea]. [Consultado el 20 de febrero de 2006] Disponible en Internet: www.unav.es/quimicayedafología/csanta/a1/aguas.

-CENAGRO (2001). Diagnóstico del Municipio de Telpaneca. Managua: Instituto Nicaragüense de Estadísticas y Censos (INEC).

-CLESCERI LENORE, S. et al. (1992). Métodos normalizados para el análisis de aguas potables y residuales. Madrid: Ediciones Díaz de Santos.

-COMITÉREGIONAL DEAGUAPOTABLEPARACONSUMOHUMANODECENTROAMÉRICA, PANAMÁ Y REPÚBLICA DOMINICANA (1994). Normas de calidad del agua para consumo humano (CAPRE) [en línea]. San Salvador, $1^{\mathrm{a}}$ ed. rev. Disponible en Internet: www.hispagua. cedex.es/siagua/datos/calidad_iberoamerica

-GOBIERNO DE LA REPÚBLICA DE NICARAGUA (2000). "Decreto No 394. Disposiciones sanitarias". La Gaceta, Diario Oficial, Managua.

-HARRIS, D. C. (1999). Quantitative Chemical Análisis [en línea]. Ed. Freeman. [Consultada el 20 de febrero de 2006]. Disponible en Internet: http:/www.es.wikipedia.org/wiki/Agua.

-Métodos normalizados para análisis de aguas potables y residuales [en línea]. [Consultada el 22 de abril de 2006] Disponible en Internet: ww.cuspide.com/detalle_libro.php. 
Encuentro 2007/ Año XXXIX, $N^{\circ} 76,57-66$

-MINSA (1998). Normas técnicas de aguas potables y residuales. Managua: DEPARTAMENTO DE TOXICOLOGÍA AMBIENTAL

-OMS (1998). Guías para la calidad del agua potable Vol. 1,2 y 3. Ginebra: OMS.

-QUIROZ, A. (s.f.). Situación del agua en Nicaragua [en línea]. [Consultada 20 de abril de 2006]. Disponible en Internet: www.menschen-recht-wasser.de/downloads. 